\title{
The Use of Ertapenem in Postoperative Polymicrobial Peritonitis - case report
}

\author{
Laura Gavril $^{*, 1,2}$, Ionela-Alina Grosu ${ }^{1}$, Lavinia Bodescu Amancei ${ }^{2}$, Ioana Grigoraș ${ }^{1,2}$ \\ 1 "Grigore T. Popa" University of Medicine and Pharmacy, Iași, ${ }^{2}$ Anesthesia and Intensive Care De- \\ partment - Regional Institute of Oncology, Iași, Romania
}

\begin{abstract}
A 59 year-old male patient diagnosed with cecal cancer, surgically treated - right hemicolectomy with ileotransverse anastomosis suddenly presented in the 5th postoperative day fever, hypotension, abdominal pain, and vomiting faeces. The intraoperatory diagnosis was postoperative peritonitis due to anastomotic leak; exploratory laparotomy, segmental colectomy, transverse ileostomy, lavage and drainage were performed. Before surgical reintervention, blood cultures were performed and empirical antiinfective therapy was started using ertapenem, vancomycin and fluconazole. A postoperative ICU admission was decided due to septic shock and MODS: acute respiratory failure, acute cardio-circulatory failure, coagulopathy and metabolic acidosis, which required complex treatment: ventilatory support, haemodynamic optimization, antibiotics, analgesia, deep venous thromboembolism prophylaxis, nutrition. In the $3^{\text {rd }}$ day after reintervention, microbiological examination of the intraoperatory collected peritoneal fluid identified a triple germ association: Escherichia coli, Enterococcus faecalis and Proteus mirabilis, which were sensitive to the chosen antibiotics; the blood cultures were sterile. After 3 days of severe evolution, the multiple organ dysfunction gradually improved and the patient was discharged from ICU 10 days later.
\end{abstract}

Keywords: postoperative polymicrobial peritonitis, Ertapenem, Carmeli Score, MODS septic shock

\section{Introduction}

Peritonitis is an inflammation of the peritoneum, the tissue that lines the inner wall of the abdomen and covers and supports most of the abdominal organs. Peritonitis is usually caused by infection from bacteria or fungi [1].

Peritonitis may result in septic shock, multiple organ dysfunction syndrome and death. Septic shock is a life-threatening condition that happens when the blood pressure drops to a dangerously low level after an infection [2, 3].

Received: April 2014; Accepted after review: June 2014; Published: June 2014

*Corresponding author: Laura Gavril, "Grigore T. Popa" University of Medicine and Pharmacy, Iași, Anesthesia and Intensive Care Department - Regional Institute of Oncology, lași, Romania. Email: cotirlet laura@yahoo.com
In any septic patient, the clinician must assess the presence of acute organ dysfunction (severe sepsis). The presence of acute organ dysfunction is often clinically recognized by the patient's signs and symptoms. Complex monitoring and laboratory data will confirm the diagnosis of organ dysfunction.

Clinical signs of organ dysfunction consist of: altered consciousness, confusion, psychosis, delirium (central nervous system dysfunction), tachypnea, hypoxemia, oxygen saturation $<90 \%$, decreased ratio of arterial oxygen vs. inspired oxygen (respiratory dysfunction), increased liver enzymes, jaundice, increased prothrombin time, hypoalbuminemia, (hepato-biliary dysfunction), tachycardia, hypotension, decreased systemic vascular resistance (cardiovascular dysfunction), 
oliguria, anuria, increased creatinine (renal failure), anemia, thrombocytopenia, abnormal coagulation tests, decreased levels of $C$ Reactive Protein (CRP), increased D-dimers (hematologic dysfunction).

The time evolution of new therapeutic principles, starting with Kirschner in the early $20^{\text {th }}$ century, significantly reduced the mortality rate associated with intra-abdominal infections over the last century [4-6] (Fig. 1). The basic strategies of modern approach consist of source control, identification of involved microorganisms, antimicrobial treatment and complex critical care.

Postoperative peritonitis is usually classified with a 3 score value on the Carmeli scale and imposes the need for first-line therapy, using a combination of broad-spectrum antibiotics, which usually includes a 2nd generation carbapenem (such as imipenem, meropenem) $[7,8]$.

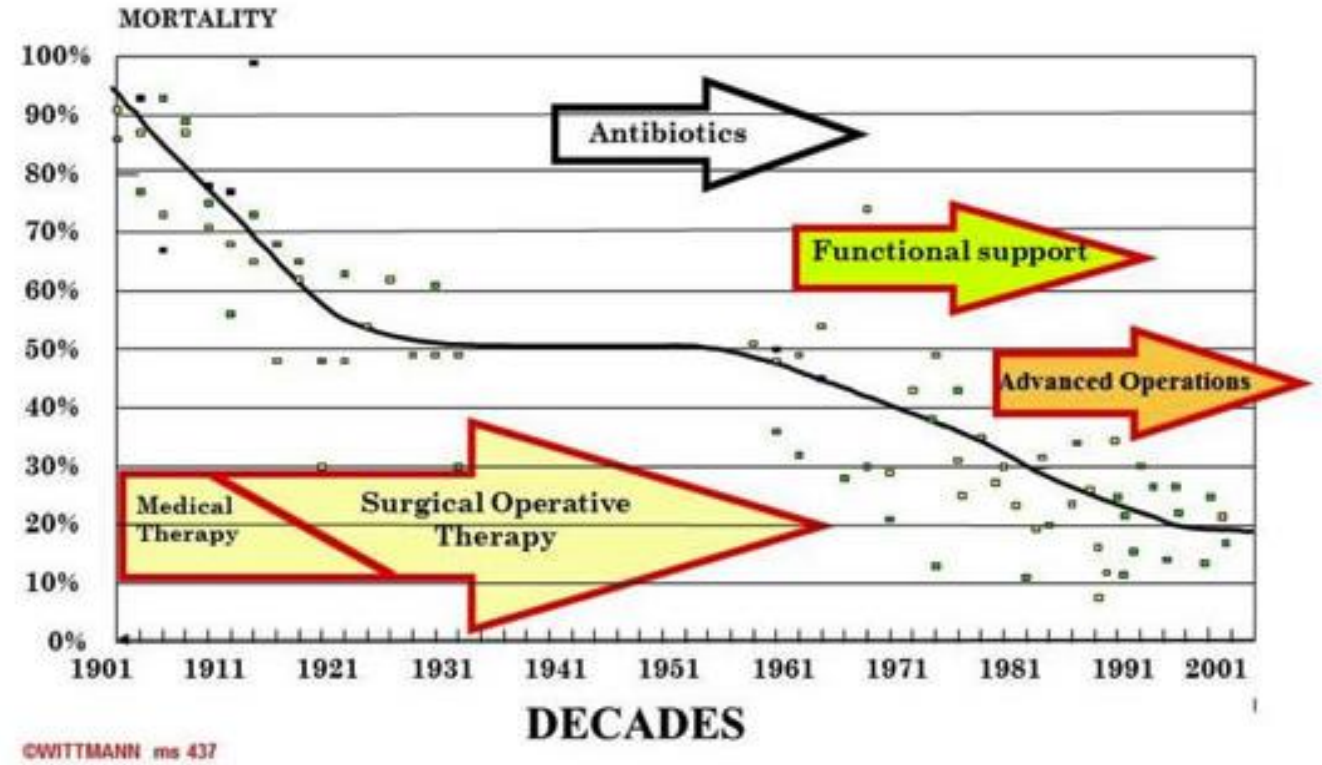

Fig. 1. Mortality over time of intra-abdominal infections [6]

\section{Case report}

A 59 year-old male patient, with cecal cancer, secondary anemia and neoplastic cachexia was admitted in Surgery Clinic of the Regional Institute of Oncology lași. Computer tomographic examination revealed bilobare liver metastases. The surgical treatment consisted in right hemicolectomy with ileotransverse anastomosis. In the first postoperative day, the patient had a favorable evolution and was discharged from Intensive care unit (ICU) after 24 hours.

In the $5^{\text {th }}$ postoperative day, the patient suddenly presented the following symptoms: fever, hypotension, abdominal pain and tenderness and vomiting faeces. Surgical reintervention was decided. The intraoperative diagnosis was postoperative peritonitis due to anastomotic leak and exploratory laparotomy, segmental colectomy, transverse ileostomy, lavage and drainage were performed.

Before surgical reintervention, blood cultures were performed and empirical antiinfective therapy was started using ertapenem (1g/day), vancomycin (1g/12h) and fluconazole $(800 \mathrm{mg} / \mathrm{day})$ and was continued for the next 3 days.

A postoperative ICU admission was decided due to septic shock and multiple organ dysfunction syndrome (MODS): acute respiratory failure, acute cardio-circulatory failure, coagulopathy, metabolic acidosis (table 1), which required complex treatment (ventilatory support, haemodynamic optimization, antibiotics, analgesia, deep venous thromboembolism prophylaxis, nutrition). 
Table 1. ICU status

\section{Intensive Care Unit status}

\begin{tabular}{llc}
\hline TAM & $65 \mathrm{mmHg}$ & Cardio-circulatory failure \\
$\mathrm{HR}$ & $95 \mathrm{bpm}$ & \\
$\mathrm{PaO}_{2} / \mathrm{FiO}_{2}$ & 235 & Acute Lung Injury (ALI) \\
$\mathrm{APTT}$ & $54 \mathrm{sec}$ & \\
INR & 1,4 & Coagulopathy/ thrombocitopenia \\
Thrombocytes & $129.000 / \mathrm{mm}^{3}$ & \\
Haemoglobin & $8 \mathrm{~g} / \mathrm{dl}$ & Anemia \\
$\mathrm{Hematocrit}$ & $25 \%$ & \\
$\mathrm{pH}$ & 7,31 & Methabolic acidosis \\
Lactate & $1,4 \mathrm{mmol} / \mathrm{I}$ & \\
CRP & $16 \mathrm{mg} / \mathrm{dl}$ & Inflammatory Syndrome \\
Procalcitonine & $\mathbf{1 , 2} \mathbf{~ n g / d l}$ & \\
\hline
\end{tabular}

In the $3^{\text {rd }}$ day after reintervention, microbiological examination of the intraoperatory collected peritoneal fluid identified a triple germ association: Escherichia coli, Enterococcus faecalis and Proteus mirabilis, which were sensitive to the chosen antibiotics. The blood cultures were sterile. After 3 days of severe evolution, the multiple organ dysfunction gradually improved and the patient was discharged from ICU 10 days later (Fig. 2).

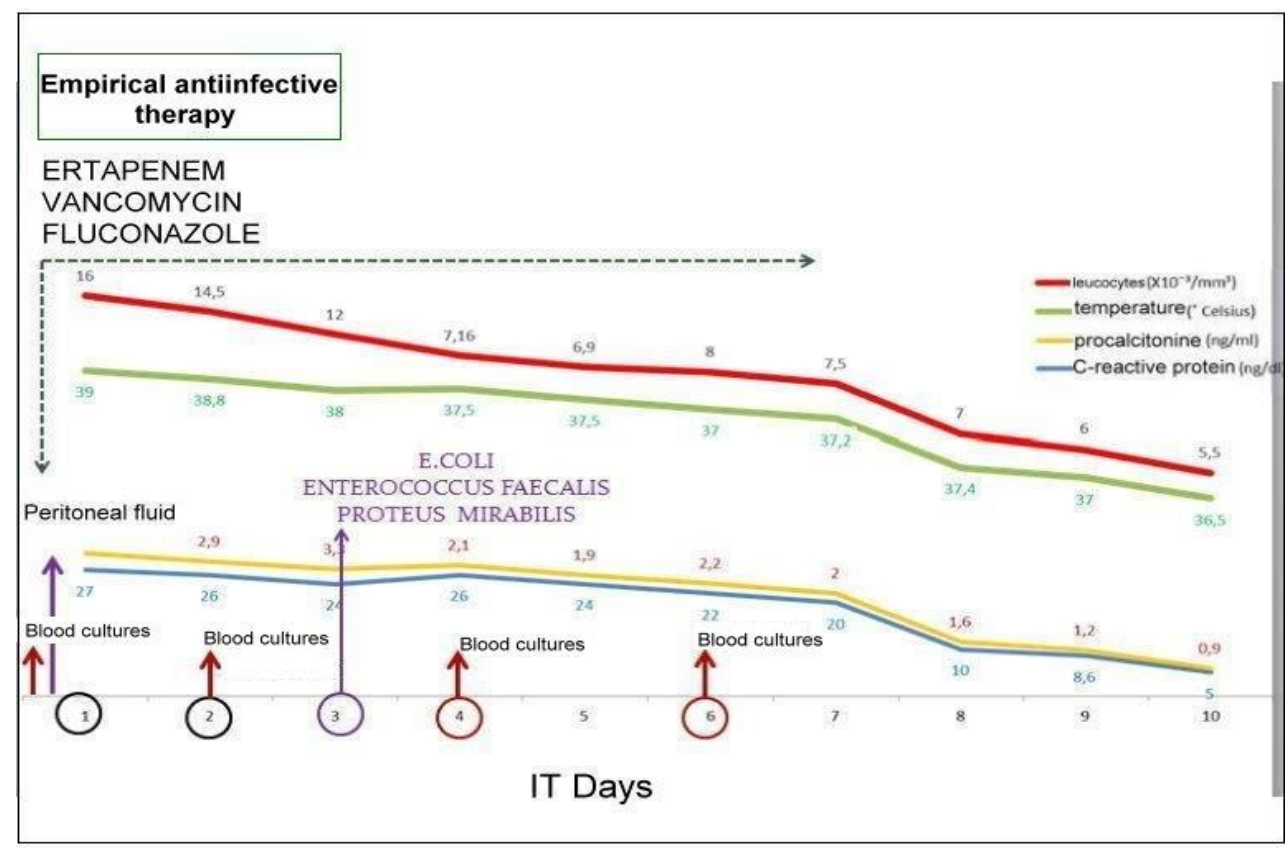

Fig. 2. ICU dynamics of inflammatory markers (fever, white blood cell count, procalcitonine and $\mathrm{C}$ reactive protein), microbiological tests and antiinfective therapy

\section{Discussions}

Patients with postoperative peritonitis are at high risk of having gram-negative multi- resistant pathogen infections and the recommended empirical antibiotherapy consists of a second generation carbapenem (imipenem, meropenem) associated with a 
coverage of gram-positive germs (mainly, Enterococcus spp.). The first generation carbapenem is recommended in case of community-acquired peritonitis.

But the use of second generation carbapenems is associated with high risk of modified hospital ecology with the emergence of highly resistant strains.

In order to choose an appropriate carbapenem agent for treatment of nosocomial infections it is important to assess the patient's risk of infection with gram-negative, multidrugresistant pathogens [8-11].

Risk factors for infection with gramnegative multidrug-resistant Entero- bacteriaceae include: recent contact with sanitary system, but without invasive procedures (e.g.: recent admissions in hospital/ day care/ hospice), recent antibiotic therapy ( $\geq 14$ days in the last 90 days), age $\geq 65$ years, patient with comorbidities (e.g.: renal failure).

Risk factors for infection with multidrugresistant Pseudomonas include: long period hospitalizations and/or infections after invasive procedures ( $>5$ days), recent antibiotic therapy ( $\geq 14$ days in the last 90 days), and multiple comorbidities (cystic fibrosis, respiratory diseases, AIDS, neutropenia, severe immune deficit) (Table 2).

Table 2. Complicated Intra-abdominal Infection Guidelines [9]

\begin{tabular}{|c|c|c|c|}
\hline & $\begin{array}{c}\text { No risk factors for } \\
\text { MDR }\end{array}$ & $\begin{array}{c}\text { Risk factors for } \\
\text { Enterobacteriaceae } \\
\text { MDR }\end{array}$ & $\begin{array}{l}\text { Risk factors for } \\
\text { Pseudomonas } \\
\text { MDR }\end{array}$ \\
\hline $\begin{array}{l}\text { Previous } \\
\text { contact with } \\
\text { sanitary } \\
\text { system }\end{array}$ & $\begin{array}{l}\text { No contact with } \\
\text { sanitary system }\end{array}$ & $\begin{array}{l}\text { Recent contact with sanitary } \\
\text { system but without invasive } \\
\text { procedures (e.g.: recent } \\
\text { admissions in hospital/ day } \\
\text { care/hospice) }\end{array}$ & $\begin{array}{l}\text { Long period hospitalizations } \\
\text { and/or infections after invasive } \\
\text { procedures } \\
\text { (>5 days) }\end{array}$ \\
\hline $\begin{array}{l}\text { Previous } \\
\text { therapy with } \\
\text { antibiotics }\end{array}$ & $\begin{array}{l}\text { No recent antibiotic } \\
\text { therapy }\end{array}$ & $\begin{array}{l}\text { Recent antibiotic therapy } \\
(\geq 14 \text { days in the last } 90 \\
\text { days })\end{array}$ & $\begin{array}{l}\text { Recent antibiotic therapy } \\
\text { ( } \geq 14 \text { days in the last } 90 \text { days) }\end{array}$ \\
\hline Patient factors & $\begin{array}{l}\text { Young patient } \\
\text { Few } \\
\text { comorbidities }\end{array}$ & $\begin{array}{l}\text { Age } \geq 65 \text { years, patient with } \\
\text { comorbidities (e.g.: renal } \\
\text { failure) }\end{array}$ & $\begin{array}{llr}\text { Patients } & \text { with } & \text { multiple } \\
\text { comorbidities } & \text { (AIDS, respiratory } \\
\text { diseases, } & \text { cystic } & \text { fibrosis, } \\
\text { neutropenia, } & \text { severe } & \text { immune } \\
\text { deficit) } & & \end{array}$ \\
\hline $\begin{array}{l}\text { Carbapenem } \\
\text { selection }\end{array}$ & $\begin{array}{l}\text { Limited use of } \\
\text { carbapenems }\end{array}$ & $\begin{array}{l}\text { Ertapenem } \\
\text { (group } 1 \text { carbapenems) }\end{array}$ & $\begin{array}{l}\text { Imipenem, meropenem, } \\
\text { doripenem } \\
\text { (group } 2 \text { carbapenems) }\end{array}$ \\
\hline
\end{tabular}

The reported patient had ongoing hospitalisation, recent surgery, one day antibiotic course (antibioprophylaxy) and no comorbidities.

The use of ertapenem in postoperative peritonitis as empirical antibiotherapy may result in several advantages: good patient outcome and improved hospital ecology.

Thus, ertapenem use is a $2^{\text {nd }}$ generation carbapenem sparing strategy, which may avoid the selection of resistant strains and preserve the Enterobacteriaceae susceptibility.

Ertapenem has little impact on the ecology of the hospital environment. The use of ertapenem in medical practice minimizes the selective pressure on multi-resistant pathogens and maintain unchanged the susceptibility profile of Enterobacteriaceae, Pseudomonas spp. enhancing susceptibility to imipenem, levofloxacin and cefepime. 
A retrospective longitudinal hospital database study, that included nine medical wards (400 beds) examined group 1 and group 2 carbapenem resistance amongst Pseudomonas aeruginosa in Israel from 2001 to 2005 [7-9]. For 139,185 patient admissions, 541,150 DDD of antibiotics, 4,637 DDD of group 2 carbapenems and 2,130 DDD of ertapenem were prescribed. Multivariate analysis showed that ertapenem was not associated with the development of imipenemresistant $P$. aeruginosa $(P=0.2)$; however, imipenem and meropenem were significantly associated with the development of imipenemresistant $P$. aeruginosa $(P=0.001)$.

\section{References}

1. Mimili M, Agca B, Altinli E, Dinc M: Importance of source control in secondary peritonitis. Ulus Travma Derg, 2002, 8(1):49-52.

2. Ozguc H, Yilmazlar T, Gurluler E, Ozen $\mathrm{Y}$, Korun N, Zorluoglu A: Staged abdominal repair in the treatment of intra-abdominal infection: analysis of 102 patients. J Gastrointest Surg, 2003, 7(5):646-651.

3. Agalar F, Eroglu E, Bulbul M, Agalar C, Tarhan OR, Sari M: Staged abdominal repair for treatment of moderate to severe secondary peritonitis. World J Surg, 2005, 29(2):240-244.

4. Teichmann W, Pohland C, Mansfeld T, Herbig B: Peritonitis: attempt to evaluate therapeutic surgical options. Chirurg, 2008, 79(4):282-289.

5. Karamarkovic AR, Popovic NM, Blagojevic ZB et al.: Damage control surgery in abdominal trauma. Acta Chir lugosl, 2010, 57(1):15-24.

6. Wittmann DH: Treatment of Peritonitis: Antibiotic concentration dynamics at the site of infection as criterion of antimicrobial chemotherapy. Habilitation. Hamburg: Medizinische Fakultät der Universität; 1984.

7. Nicolau DP, Carmeli Y, Crank CW, et al: Carbapenem stewardship: does ertapenem affect Pseudomonas susceptibility to other

\section{Conclusions}

The results of in vitro and clinical studies showed that the use of ertapenem did not decrease susceptibility of $P$. aeruginosa, Enterobacteriaceae or other gram-negative pathogens to carbapenems [7, 12].

The treatment with ertapenem was effective in a patient with postoperative peritonitis, septic shock and MODS. Ertapenem, used as first-line therapy, circumvents the need for a $2^{\text {nd }}$ generation carbapenem (imipenem, meropenem) and preserves the ecology of the hospital.

carbapenems? A review of the evidence. Int $J$ Antimicrob Agents, 2012, 39(1):11-15.

8. Carmeli Y, Lidji SK, Shabtai E, Navon Venezia S, Schwaber MJ: The effects of group 1 versus group 2 carbapenems on imipenem resistant Pseudomonas aeruginosa: an ecological study. Diagn Microbiol Infect Dis, 2011, 70:367-372.

9. Solomkin JS, Mazuski JE, Bradley JS et al: Diagnosis and management of complicated intra-abdominal infection in adults and childreans: guidelines by the Surgical Infection Society and the Infectious Diseases Society of America. Clin Infect Dis, 2010, 50:133-164.

10. Swenson BR, Metzger R, Hedrick TL, et al: Choosing antibiotics for intra-abdominal infections: what do we mean by "high risk"? Surg Infect (Larchmt), 2009, 10:29-39.

11. Sartelli M, Catena F, Coccolini F, Pinna AD: Antimicrobial management of intra-abdominal infections: Literature's guidelines. World $J$ Gastroenterol, 2012, 18(9): 865-871.

12. Falagas ME, Peppas G, Makris GC, Karageorgopoulos DE, Matthaiou DK: Metaanalysis: ertapenem for complicated intraabdominal infections. Aliment Pharmacol Ther, 2008, 27(10):919-931. 